This document was prepared in conjunction with work accomplished under Contract No. DE-AC09-96SR18500 with the U. S. Department of Energy.

\title{
DISCLAIMER
}

This report was prepared as an account of work sponsored by an agency of the United States Government. Neither the United States Government nor any agency thereof, nor any of their employees, nor any of their contractors, subcontractors or their employees, makes any warranty, express or implied, or assumes any legal liability or responsibility for the accuracy, completeness, or any third party's use or the results of such use of any information, apparatus, product, or process disclosed, or represents that its use would not infringe privately owned rights. Reference herein to any specific commercial product, process, or service by trade name, trademark, manufacturer, or otherwise, does not necessarily constitute or imply its endorsement, recommendation, or favoring by the United States Government or any agency thereof or its contractors or subcontractors. The views and opinions of authors expressed herein do not necessarily state or reflect those of the United States Government or any agency thereof. 
Keywords: Waste processing, cesium, ion exchange Retention: Permanent

\section{DIGESTION OF CRYSTALLINE SILICOTITANATE (CST)}

D. D. Walker

November 4, 2004

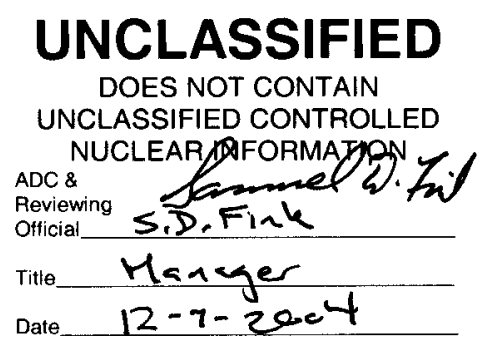

Westinghouse Savannah River Company

Savannah River Site

Aiken, SC 29808

Prepared for the U.S. Department of Energy Under

Contract Number DE-AC09-96SR18500

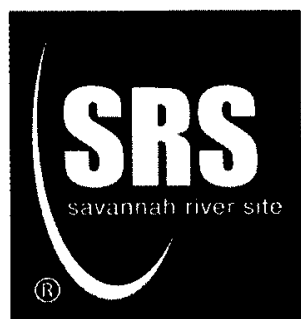


This page was intentionally left blank 


\section{TABLE OF CONTENTS}

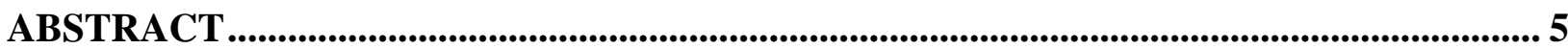

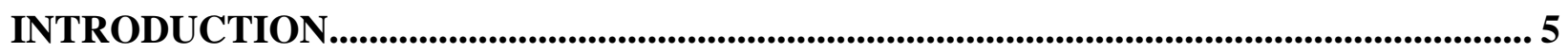

TEST CONDITIONS AND PROTOCOL .........................................................................

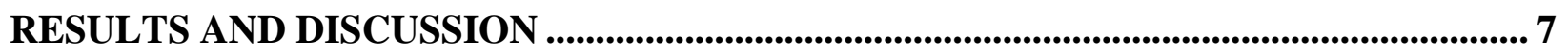

SUMMARY AND RECOMMENDATIONS........................................................................... 14

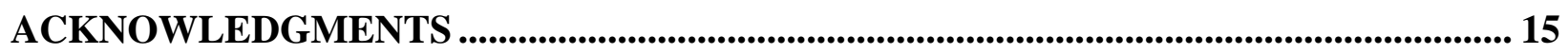

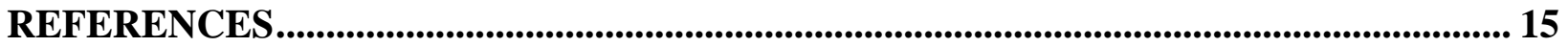




\section{LIST OF FIGURES}

FIGURE 1. Experimental Apparatus ......................................................................................... 7

FIGURE 2. Color Changes during Hydrogen Peroxide Addition and Neutralization...... 8

FIGURE 3. Optical Microscope Images of IONSIV ${ }^{\circledR}$ IE-911 Beads and Amorphous

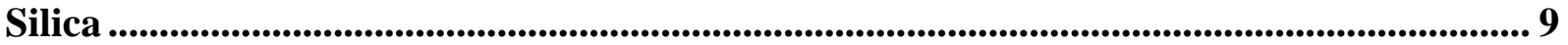

FIGURE 4. Gas Generation during IONSIV ${ }^{\circledR}$ IE-911 Digestion and Neutralization ..... 13

\section{LIST OF TABLES}

TABLE I. Effect of Stirring ......................................................................................................... 9

TABLE II. Effect of pH and Anion ................................................................................... 10

TABLE III. Effect of Acid Concentration ...................................................................... 10

TABLE IV. Effect of Fluoride ............................................................................................... 11

TABLE V. Effect of Hydrogen Peroxide Addition Rate ................................................... 12

TABLE VI. Effect of Amount of Hydrogen Peroxide ........................................................ 12 


\title{
DIGESTION OF CRYSTALLINE SILICOTITANATE (CST)
}

\author{
By D. D. Walker
}

\begin{abstract}
Researchers tested methods for chemically dissolving crystalline silicotitanate (CST) as a substitute for mechanical grinding to reduce particle size before vitrification. Testing used the commercially available form of CST, UOP IONSIV ${ }^{\circledR}$ IE-911. Reduction of the particle size to a range similar to that of the glass frit used by the Defense Waste Processing Facility (DWPF) could reduce problems with coupling cesium ion exchange to the vitrification process. This study found that IONSIV ${ }^{\circledR}$ IE-911 dissolves completely using a combination of acid, hydrogen peroxide, and fluoride ion. Neutralization of the resulting acidic solution precipitates components of the IONSIV ${ }^{\circledR}$ IE-911. Digestion requires extremely corrosive conditions. Also, large particles may reform during neutralization, and the initiation and rate of gas generation are unpredictable. Therefore, the method is not recommended as a substitute for mechanical grinding.
\end{abstract}

\section{INTRODUCTION}

The Savannah River Site stores 37 million gallons of high level radioactive waste in large underground tanks. The majority of the waste exists in the form of damp salt cake. The salt cake will be dissolved in water prior to removal from the storage tanks. Following removal, the salt solution will be decontaminated prior to disposal. Researchers from Oak Ridge National Laboratory (ORNL) and the Savannah River National Laboratory (SRNL) proposed a Small Column Ion Exchange process for removing cesium from the dissolved salt cake. ${ }^{1}$ This ion exchange process requires passing the salt solution through a column of sorbent containing approximately 375-gallon of UOP IONSIV ${ }^{\circledR}$ IE-911. This granular form of CST eventually transfers to the DWPF for vitrification.

This test program examined chemical digestion methods for the reduction of IONSIV ${ }^{\circledR} \quad$ IE-911 to a size compatible with the DWPF feed stream. Chemical digestion offers an alternative to the current proposal to mechanically grind the IONSIV ${ }^{\circledR}$ IE-911. Previous work with hydrogen peroxide suggested that this reagent may effectively degrade the IONSIV ${ }^{\circledR}$ IE-911. ${ }^{2}$ Texas A\&M researchers reported significant loss of cesium sorption when IONSIV ${ }^{\circledR}$ IE-911 was treated with $1 \mathrm{M}$ hydrogen peroxide under alkaline conditions. Testing targeted a maximum particle size of 177 micron (80 mesh), similar to the current frit size used by the DWPF (80 to 200 mesh). ${ }^{3}$

The Department of Energy's Office of Cleanup Technologies authorized and funded this task through an Oak Ridge National Laboratory proposal titled "Small Column Ion Exchange System Utilizing Crystalline Silicotitanate for Cesium Removal from Low Curie Salt Waste (Phase 2)." SRNL researchers performed the tests based on a scoping plan. ${ }^{4}$ 


\section{TEST CONDITIONS AND PROTOCOL}

The testing primarily examined hydrogen peroxide as a chemical method for particle size reduction. Testing included additional chemical (i.e., $\mathrm{pH}$, coordinating anions) and physical (i.e., temperature, mixing method) conditions. Researchers examined the following treatment parameters to determine their effect on size reduction.

- Stoichiometry (ratio of hydrogen peroxide to mass of IONSIV ${ }^{\circledR}$ IE-911)

- Temperature (22 and $\left.50^{\circ} \mathrm{C}\right)$

- $\mathrm{pH}$ (acidic, neutral, or basic)

- Coordinating anions (nitrate, sulfate, chloride, or fluoride)

- Duration of addition

A typical experiment incorporated the following steps.

(1) Preparation of solutions and sample.

Researchers prepared slurries of caustic washed IONSIV ${ }^{\circledR}$ IE-911 (2.2 g)

suspended in a heated $\left(22\right.$ or $\left.50^{\circ} \mathrm{C}\right)$ aqueous solution $(90 \mathrm{~mL})$ of the desired composition (typically $3 \mathrm{M}$ nitric acid). When required, sodium fluoride ( $0.4 \mathrm{~g}$ or $\sim 1 \mathrm{M}$ ) was dissolved in the hydrogen peroxide solution (10 $\mathrm{mL}$ of $30 \mathrm{wt} \%$ ).

(2) Addition of reagent solutions to IONSIV ${ }^{\circledR}$ IE-911.

A syringe pump transferred the hydrogen peroxide solution to the stirred IONSIV ${ }^{\circledR}$ IE-911 slurry (duration: 10 minutes to 6 hours). Stirring continued for 1 hour following the last peroxide addition. Researchers visually monitored the reaction for color changes, gas generation, and solids disappearance or formation.

(3) Neutralization.

Following the 1 hour digestion, researchers cooled the reaction solution to room temperature $\left(\sim 22^{\circ} \mathrm{C}\right)$ and neutralized by adding sodium hydroxide solution $(3 \mathrm{M})$ over a short period of time (usually much shorter than the duration of the hydrogen peroxide addition).

(4) Size measurement.

After neutralization, researchers rinsed the solids with water in an 80 mesh sieve, measured the volume and weight (after drying) of the solids that failed to pass through the sieve, and examined the particles using a light microscope. In some cases, $\mathrm{x}$-ray diffraction (XRD) or dispersive $\mathrm{x}$-ray fluorescence spectrometry analysis of the solids determined their composition.

Figure 1 shows the experimental apparatus. A water bath maintained the IONSIV ${ }^{\circledR}$ IE-911 slurry at constant temperature. A paddle stirrer in the graduated cylinder provided agitation sufficient to move the IONSIV ${ }^{\circledR}$ IE-911 particles on the bottom of the cylinder. A syringe pump regulated the rate of addition of the hydrogen peroxide solution. Addition of peroxide occurred at the cylinder wall at a point above the surface of the slurry. 


\section{FIGURE 1. Experimental Apparatus}

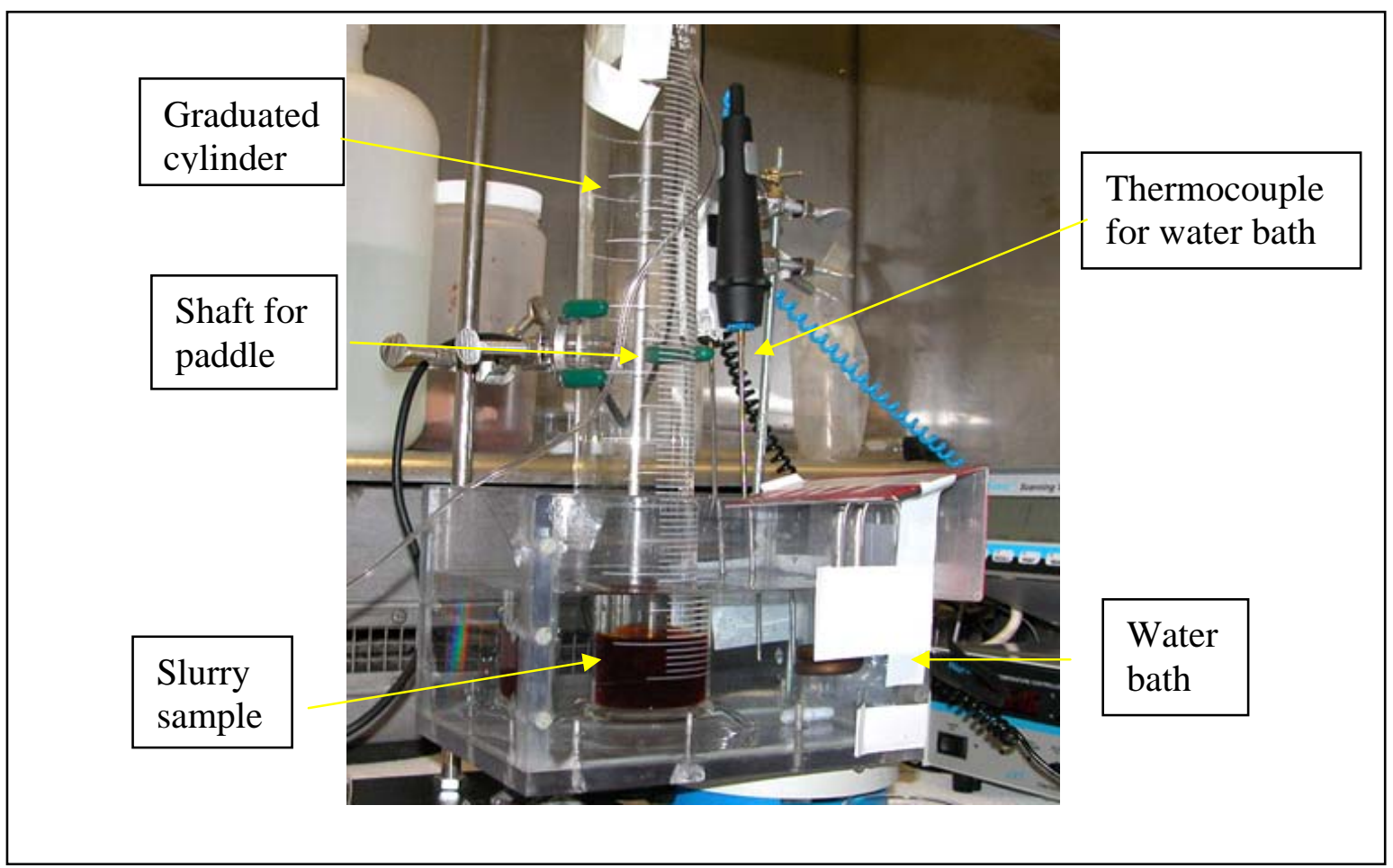

\section{RESULTS AND DISCUSSION}

\section{General Observations}

During the course of the reaction with hydrogen peroxide, the solution color changes, the solids partially or completely dissolve, and, in some cases, solids reappear during neutralization. Figure 2 shows typical color changes during the addition of hydrogen peroxide. Initially, the solution appears colorless with particles visible and not evenly distributed because of the low rate of stirring. Peroxide addition gradually changes the solution color to yellow, then orange, and finally red. In reactions with intense color changes, nearly all of the solids disappear by the end of peroxide addition, leaving a clear or hazy solution. Neutralization causes the color to return to yellow and become opaque due to precipitation of components of the IONSIV ${ }^{\circledR}$ IE-911. The formation of soluble peroxo-titanium complexes likely cause the yellow, orange, and red colors. $^{5}$

\section{$\underline{\text { Identification of Solids }}$}

After neutralization, researchers collected the solids in an 80-mesh sieve, washed the solids with water, and examined the washed solids using an optical microscope. Optical microscopy and XRD analysis showed that the solids could be categorized into two classes. The first class included IONSIV ${ }^{\circledR}$ IE-911 beads, either whole or broken into fragments. The second class contained precipitated components from the IONSIV ${ }^{\circledR}$ IE-911. XRD showed that the precipitated components were amorphous. Energy dispersive x-ray fluorescence spectrometry 


\section{FIGURE 2. Color Changes during Hydrogen Peroxide Addition and Neutralization}

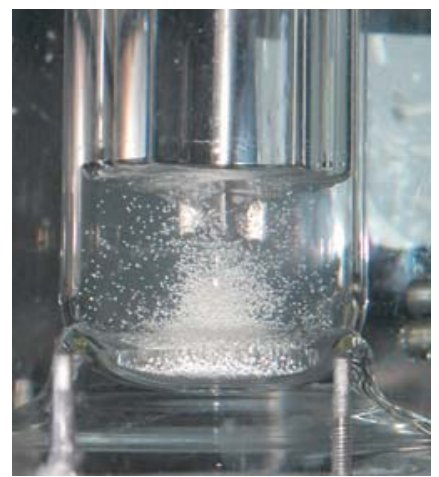

Before peroxide addition.

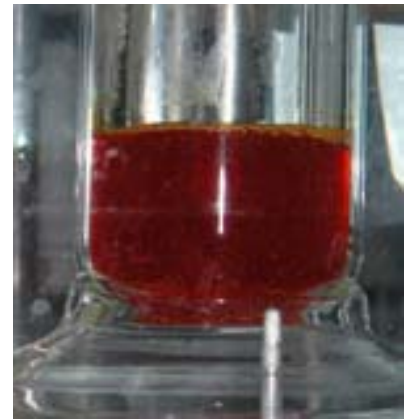

End of peroxide addition.

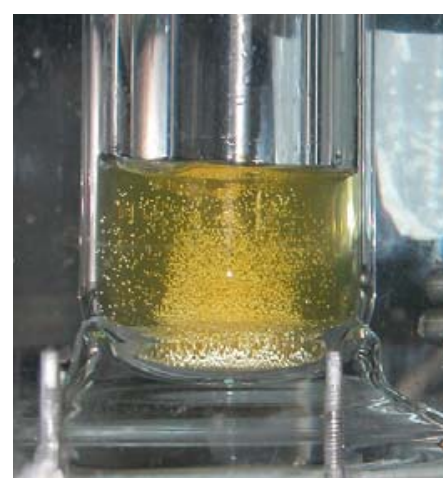

Start of peroxide addition.

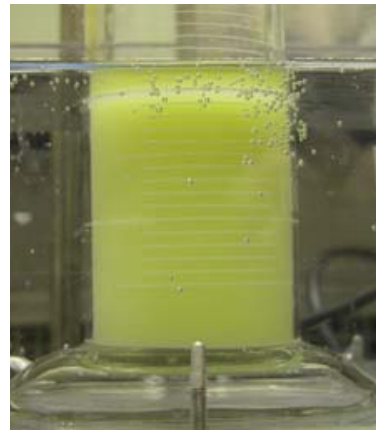

After neutralization.

revealed the elemental composition of the amorphous solids. Amorphous silica constituted the majority of the precipitated product. However, small amounts of three other phases occurred. One such phase contained Si, Zr, and Ti (no Nb). Other phases contained Si and $\mathrm{Nb}$ (no Zr or $\mathrm{Ti}$ ), or $\mathrm{Nb}$ alone. Examination by optical microscope could distinguish resin beads from precipitated solids. Figure 3 shows examples of the two most common solid phases. Resin beads appeared as entire or broken spheres with a rough surface. Precipitated solids (silica) appeared irregular in shape, smaller than resin beads, with a luster to their surface.

\section{Effect of Stirring}

Preliminary tests indicated that the method of stirring affected the results. Table I summarizes the results of tests that were either not stirred, stirred with a Teflon-coated stir bar, or stirred with a paddle. The results suggest that the stir bar mechanically grinds the particles, yielding fewer solids larger than 80 mesh. Subsequent testing used a paddle stirrer to minimize mechanical reduction of the particle size. 


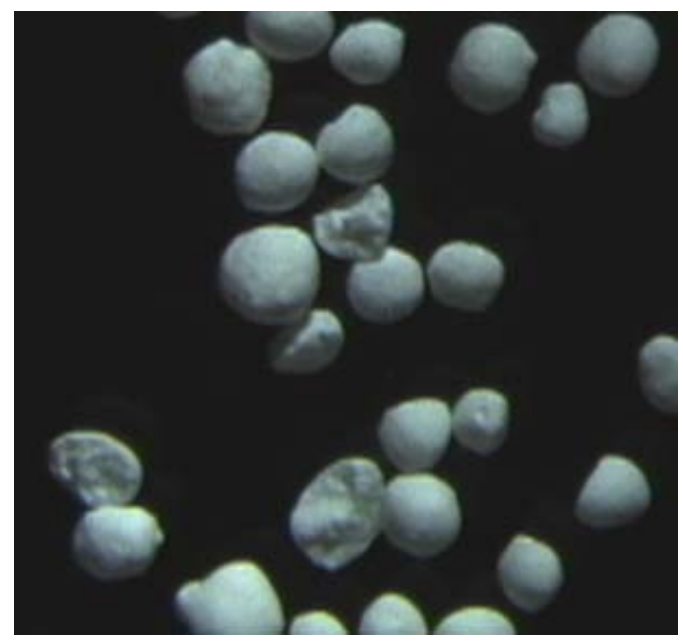

IONSIV $^{\circledR}$ IE-911 beads.

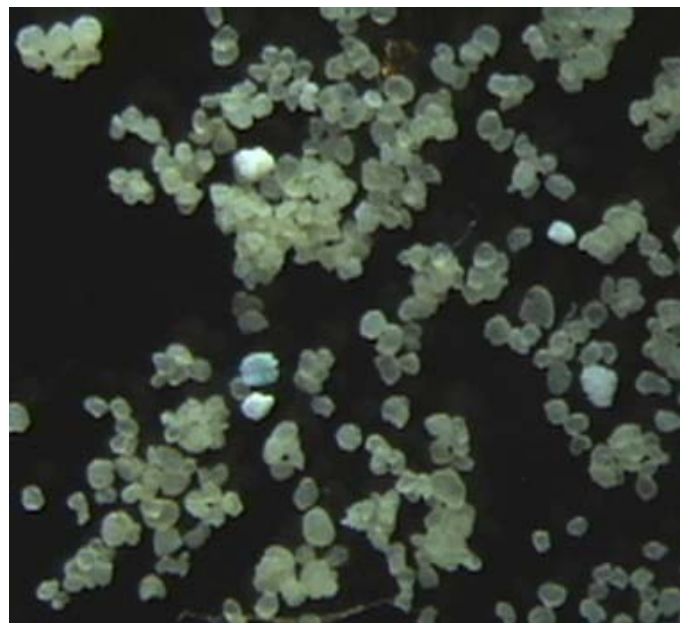

Amorphous silica.

TABLE I. Effect of Stirring

$\underline{\text { Solution }}$

Water, control (no $\mathrm{H}_{2} \mathrm{O}_{2}$ )

Water, with peroxide

$3 \mathrm{M} \mathrm{HNO}_{3}$, with peroxide
Solids (wt \% of initial)*

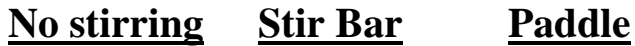

$91 \quad 55 \quad 93$

$73 \quad 9 \quad 91$

$82 \quad 55$

${ }_{\AA_{\text {IONSIV }}}^{\circledR}$ IE-911 (2.2 g) suspended in $90 \mathrm{~mL}$ of solution at $25^{\circ} \mathrm{C}$. Hydrogen peroxide $(10 \mathrm{~mL}$ of $30 \mathrm{wt} \%$ ) added at $1 \mathrm{~mL} / \mathrm{min}$ (duration: 10 minutes). Light microscope examination indicated that the residual solids were IONSIV ${ }^{\circledR}$ IE-911 beads.

*Solids larger than 80 mesh following neutralization.

\section{Effect of pH and Anion}

Table II lists results from tests comparing differences in $\mathrm{pH}$ and the anion. The results indicate that no significant size reduction occurs in neutral or alkaline solution, but significant changes occur in acidic solution. Use of chloride, a potential coordinating anion that could help solubilize IONSIV ${ }^{\circledR}$ IE-911 components, did not appear to offer a significant improvement over other acids. Sulfuric acid proved most effective, although it exceeded the performance of nitric acid only slightly. The difference may arise from the higher acidity of the diprotic sulfuric acid compared to monoprotic nitric acid. Nitric acid is potentially the least objectionable acid of the three from a tank farm or DWPF processing perspective. 
TABLE II. Effect of pH and Anion ${ }^{\S}$

\section{$\underline{\text { Solution }}$}

Water, no $\mathrm{H}_{2} \mathrm{O}_{2}$ (control)

$0.1 \mathrm{M} \mathrm{NaOH}$

Water

$3 \mathrm{M} \mathrm{HCl}$

$3 \mathrm{M} \mathrm{HNO}_{3}$

$3 \mathrm{M} \mathrm{H}_{2} \mathrm{SO}_{4}$

\section{$\underline{\text { Solids (\% of initial weight)* }}$}

99

82

94

40

14

10

${ }^{\S}$ IONSIV $^{\circledR}$ IE-911 (2.2 g) suspended in $90 \mathrm{~mL}$ of solution at $50{ }^{\circ} \mathrm{C}$. Hydrogen peroxide $(10 \mathrm{~mL}$ of $30 \mathrm{wt} \%$ ) added at $5 \mathrm{~mL} / \mathrm{hr}$ (duration 2 hours). Light microscope examination indicated that the residual solids were IONSIV ${ }^{\circledR}$ IE-911 beads in the first four tests listed, and precipitated solids in the last two tests listed.

*Solids larger than 80 mesh following neutralization.

\section{Effect of Acid Concentration}

Increasing the acid concentration improves size reduction of the IONSIV ${ }^{\circledR}$ IE-911. Table III lists results of tests using nitric acid concentrations from $0.3 \mathrm{M}$ to $15.4 \mathrm{M}$ (concentrated). The optimum value appears near $1 \mathrm{M}$ with fluoride present, but higher than $3 \mathrm{M}$ in the absence of fluoride.

\section{TABLE III. Effect of Acid Concentration ${ }^{\S}$}

\section{$\underline{\text { Solution }}$}

$0.3 \mathrm{M} \mathrm{HNO}_{3}$

$1 \mathrm{M} \mathrm{HNO3}$

$3 \mathrm{M} \mathrm{HNO}_{3}$

$15 \mathrm{M} \mathrm{HNO}_{3}$

\begin{tabular}{ll}
\multicolumn{2}{c}{ Solids (\% of initial weight)* } \\
\cline { 2 - 2 } Without $\mathbf{F}^{-}$ & $\frac{\text { With F}^{-}}{34}$ \\
\hline Not tested & 0.01 \\
Not tested & $2\left(25^{\circ} \mathrm{C}\right) ; 7,5,5\left(50^{\circ} \mathrm{C}\right)$ \\
14 & Not tested
\end{tabular}

${ }^{\S_{\text {IONSIV }}}{ }^{\circledR}$ IE-911 (2.2 g) suspended in $90 \mathrm{~mL}$ of solution at $50{ }^{\circ} \mathrm{C}$ (unless otherwise noted). NaF $(0.4 \mathrm{~g})$ dissolved in the hydrogen peroxide solution. Hydrogen peroxide $(10 \mathrm{~mL}$ of $30 \mathrm{wt} \%)$ addition rate equaled $5 \mathrm{~mL} / \mathrm{hr}$ (duration: 2 hours). Light microscope examination indicated that the residual solids were IONSIV ${ }^{\circledR} \mathrm{IE}-911$ beads in the $15 \mathrm{M} \mathrm{HNO}_{3}$ test at $25^{\circ} \mathrm{C}$ without fluoride; all other tests yielded precipitated solids.

*Solids larger than 80 mesh following neutralization. 


\section{Effect of Fluoride}

Personnel tested the impact of adding fluoride ion to the digestion mixture. Fluoride complexes silica and metals, thus promoting dissolution. The results in Table IV show the effect of adding sodium fluoride under various conditions. At moderate acid concentrations, addition of fluoride ion (as sodium fluoride) improved digestion and size reduction of the IONSIV ${ }^{\circledR}$ IE-911. Fluoride does not improve digestion in neutral or alkaline solutions, but helps in acid. Under acid conditions, fluoride reduces the amount of acid required to obtain complete digestion. Unless otherwise specified, the tests with sodium fluoride used $0.4 \mathrm{~g}$ of $\mathrm{NaF}$ dissolved in the hydrogen peroxide solution (usually $10 \mathrm{~mL}$ ). This corresponds to a peroxide-to-metal mole ratio of $1: 3$ where the moles of metal equals the sum of $\mathrm{Si}, \mathrm{Nb}, \mathrm{Ti}$, and $\mathrm{Zr}$.

\section{Effect of Hydrogen Peroxide Addition Rate}

Table V lists results of experiments showing the effect of the rate of addition of hydrogen peroxide. Researchers added 10 milliliters of peroxide solution over 2 , 8, or 24 hours, and in the presence or absence of fluoride ion. In the absence of fluoride, durations longer than 2 hours showed an advantage over shorter durations. With fluoride present, no advantage resulted from durations longer than 2 hours.

TABLE IV. Effect of Fluoride ${ }^{\S}$

\begin{tabular}{llc} 
Solution & NaF (g) & (\% of initial weight)* \\
\cline { 2 - 3 } $0.1 \mathrm{M} \mathrm{NaOH}$ & 0 & 82 \\
Water & 0.4 & 82 \\
& 0 & 94 \\
$0.3 \mathrm{M} \mathrm{HNO}_{3}$ & 0.4 & 95 \\
$1 \mathrm{M} \mathrm{H} \mathrm{NO}_{3}$ & 0.4 & 34 \\
$3 \mathrm{M} \mathrm{H} \mathrm{NO}_{3}$ & 0.4 & $0.01,<2$ \\
& 0 & 14 \\
& 0.1 & 1 \\
& 0.4 & $7,5,5$
\end{tabular}

\footnotetext{
${ }_{\text {§} \text { Tests used } 2.2 \mathrm{~g} \text { of IONSIV }}^{\circledR}$ IE-911 suspended in $90 \mathrm{~mL}$ of solution at $50{ }^{\circ} \mathrm{C}$. NaF, when used, was dissolved in the hydrogen peroxide $(10 \mathrm{~mL}$ of $30 \mathrm{wt} \%)$. Hydrogen peroxide addition rate equaled $5 \mathrm{~mL} / \mathrm{hr}$ (duration: 2 hours). The final solids in the water test were identified as IONSIV $^{\circledR}$ IE-911 beads; all other tests yielded precipitated solids.

*Solids larger than 80 mesh following neutralization.
} 
TABLE V. Effect of Hydrogen Peroxide Addition Rate ${ }^{\S}$

Duration of addition

$2 \mathrm{hr}$

$8 \mathrm{hr}$

$24 \mathrm{hr}$

\section{Solids (wt \% of initial)* \\ No fluoride With fluoride}

$\begin{array}{rl}14 & 7,5,5^{* *} \\ 2 & 6 \\ 5 & 7\end{array}$

${ }_{\S}$ IONSIV $^{\circledR} \mathrm{IE}-911(2.2 \mathrm{~g})$ suspended in $90 \mathrm{~mL}$ of $3 \mathrm{M} \mathrm{HNO}_{3}$ at $50{ }^{\circ} \mathrm{C}$. When present, $\mathrm{NaF}(0.4$ g) was dissolved in the hydrogen peroxide ( $10 \mathrm{~mL}$ of $30 \mathrm{wt} \%)$. In all cases, the solids were largely precipitated components.

* Solids larger than 80 mesh following neutralization.

** Triplicate tests at the same conditions.

\section{Effect of Amount of Hydrogen Peroxide}

Most tests in this study used $10 \mathrm{~mL}$ of $30 \mathrm{wt} \%$ hydrogen peroxide solution to treat $2.2 \mathrm{~g}$ of IONSIV $^{\circledR}$ IE-911. Sandia researchers analyzed caustic washed IONSIV ${ }^{\circledR}$ IE-911 and reported the following formula: $\left\{\left[\mathrm{Na}_{3} \mathrm{Si}_{2}\left(\mathrm{Nb}_{3}{ }_{3} \mathrm{Ti}_{7}\right)_{4} \mathrm{O}_{13}(\mathrm{OH})_{4} \mathrm{H}_{2} \mathrm{O}\right]+0.93 \mathrm{Zr}(\mathrm{OH})_{4}\right\}{ }^{6}$ The standard protocol (10 mL of $30 \mathrm{wt} \%$ hydrogen peroxide) contains approximately $0.1 \mathrm{~mole}$ of peroxide. Based on the Sandia stoichiometry for the IONSIV ${ }^{\circledR}$ IE-911, 2.2 grams contains approximately 0.0075 moles of titanium. Titanium represents the most likely component attacked by peroxide. Thus, the standard protocol uses more than 10 times the stoichiometric quantity of peroxide needed to form a 1:1 titanium peroxo species in solution. Table VI shows results from tests using different amounts of hydrogen peroxide. In the presence of fluoride, addition of a large excess of peroxide appears to have relatively little impact on the amount of IONSIV ${ }^{\circledR}$ IE-911 that dissolves.

\section{TABLE VI. Effect of Amount of Hydrogen Peroxide ${ }^{\S}$}

$\begin{array}{ll}\text { Amount } & \text { Solids (wt \% of initial)* } \\ 1 \mathrm{~mL} & 2,1,1 \\ 2 \mathrm{~mL} & 3,1 \\ 4 \mathrm{~mL} & 2,5 \\ 10 \mathrm{~mL} & 7,5,5\end{array}$

${ }_{\S}$ IONSIV $^{\circledR}$ IE-911 (2.2 g) suspended in $90 \mathrm{~mL}$ of $3 \mathrm{M} \mathrm{HNO}_{3}$ at $50{ }^{\circ} \mathrm{C}$. Hydrogen peroxide added over 2 hours. In all cases, the solids were precipitated components.

*Solids larger than 80 mesh following neutralization. 


\section{Gas Generation}

Preliminary tests showed that the start of gas generation varied. In some cases, gas generation commenced during peroxide addition if addition occurred over a short duration (10 minutes). In other cases, gas generation delayed as much as an hour after the peroxide was added. The generation rate varied considerably, sometimes being rapid enough to cause the slurry to foam to several times its initial volume. In other cases it occurred slowly with little foaming. Researchers noted that delayed gas evolution was accompanied by significant heat generation. Following the initial tests, all additions occurred over durations of 2 hours or longer. At slow hydrogen peroxide addition rates, gas evolution did not produce excessive foaming problems.

Because of these initial observations, subsequent tests relied on slow addition of the hydrogen peroxide in an attempt to maintain a low concentration of unreacted hydrogen peroxide. This approach was not completely successful. Figure 4 shows gas evolution during a later test in which peroxide addition occurred over a period of 2 hours. No significant amount of gas generation occurred until neutralization began at 4 hours. In this case, the volume of gas generated $(1 \mathrm{~L})$ was very close to the theoretical amount from the decomposition of peroxide by the following reaction stoichiometry.

$$
\mathrm{H}_{2} \mathrm{O}_{2} \rightarrow \mathrm{H}_{2} \mathrm{O}+1 / 2 \mathrm{O}_{2}
$$

Based on this stoichiometry, we expected $1180 \mathrm{~mL}$ of gas and obtained $1090 \mathrm{~mL}$, in close agreement with the stoichiometry shown above.

\section{FIGURE 4. Gas Generation during IONSIV $^{\circledR}$ IE-911 Digestion and Neutralization}

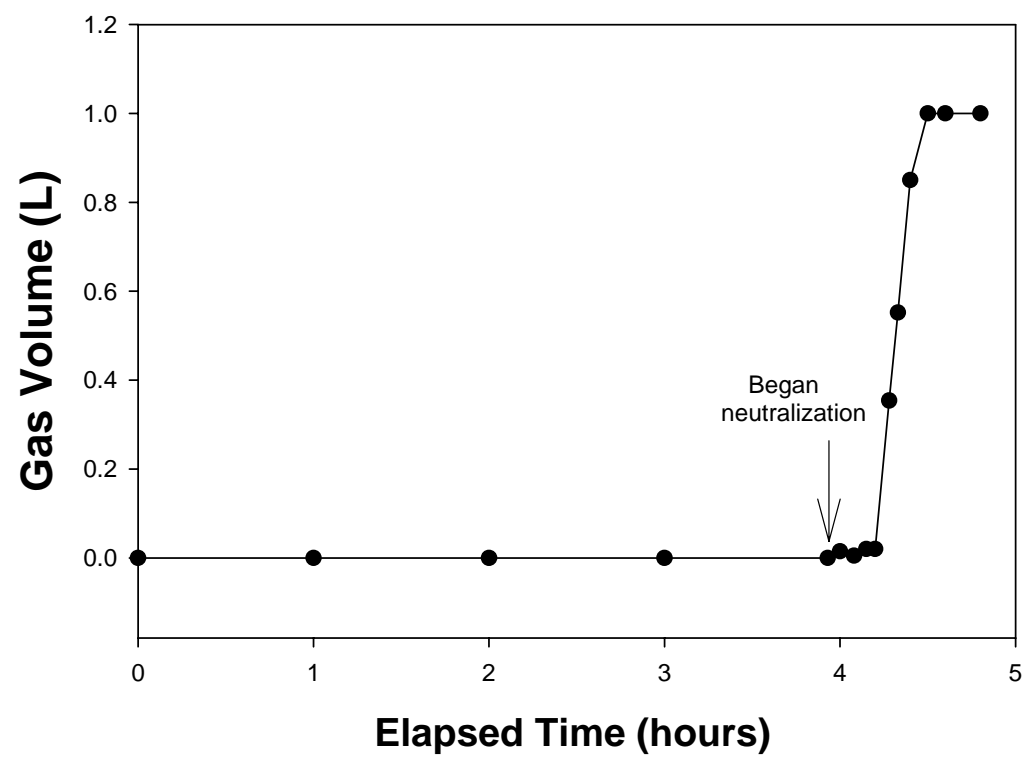




\section{SUMMARY AND RECOMMENDATIONS}

The tests demonstrated that IONSIV ${ }^{\circledR}$ IE-911 beads will dissolve using a combination of acid, hydrogen peroxide, and fluoride ion. In all cases attempted, non-acidic conditions (either neutral or alkaline) failed to dissolve major amounts of IONSIV ${ }^{\circledR}$ IE-911. Nitric acid concentrations as low as $1 \mathrm{M}$ in the presence of fluoride dissolved virtually all of the IONSIV ${ }^{\circledR}$ IE-911. Digestion also occurred without fluoride present by using concentrated nitric acid (15 M).

The results of the tests using different methods of stirring suggest that minimal grinding action may greatly influence the size reduction. Combining chemical and mechanical methods may prove more efficient at size reduction than either method alone.

The digestion process could occur in a module that replaces the grinder module inside a waste tank, or, alternatively, at a more distant location (i.e., in the DWPF). A digestion process located in the tank farm requires neutralization of the acid solution prior to transfer to a waste tank or through existing transfer lines. The results of this study show that neutralization precipitates silica and other components as particles larger than 80 mesh. Researchers performed the neutralizations as rapidly as safely feasible in an effort to produce a very fine precipitate. The results show that this approach was not entirely effective. Additional work investigating the neutralization might reveal conditions that result in a finer precipitate. Neutralization in the DWPF presents the problem of corrosion of the transfer line or DWPF piping

This testing identified three obstacles that must be overcome to use chemical digestion for size reduction of IONSIV ${ }^{\circledR}$ IE-911. First, although a variety of conditions and reagent choices could accomplish digestion of IONSIV ${ }^{\circledR}$ IE-911, all are extremely corrosive. None appear easily adaptable to the tank farm or DWPF. Second, the potential formation of large particles from neutralizing the acid solution in subsequent processing could undo the size reduction achieved by the corrosive chemicals. Third, the unpredictable nature of gas generation from decomposition of peroxide to oxygen gas represents a difficult challenge to the safe operation of the process. Based on these findings, the author does not recommend chemical digestion as a substitute for mechanical grinding. 


\section{ACKNOWLEDGMENTS}

The author thankfully acknowledges the many helpful discussions and suggestions from Charles E. Coleman, who had previously examined methods for dissolving IONSIV ${ }^{\circledR}$ IE-911 for analytical purposes. The author also acknowledges the contribution of Betty H. Croy (SRNL) who performed the digestion tests.

\section{REFERENCES}

${ }^{1}$ J. F. Walker, "Small Column Ion Exchange System Utilizing Crystalline Silicotitanate for Cesium Removal from Low Curie Salt Waste (Phase 2)", Oak Ridge National Laboratory, September 11, 2003.

${ }^{2}$ C. V. Philip and R. G. Anthony, "Crystalline Silicotitanate Ion Exchange Support for Salt Alternatives," Final Report for Project KE-49242-0, Department of Chemical Engineering, Texas A\&M University, November 29, 2000.

${ }^{3}$ Westinghouse Savannah River Company, "Specification for Procurement of DWPF Glass Frit," Specification No. X-SPP-S-00018, September 17, 2003.

${ }^{4}$ D. D. Walker, "Scoping Plan for Crystalline Silicotitanate Dissolution Tests", SRT-LWP-2004-00008, January 12, 2004.

${ }^{5}$ F. A. Cotton and G. Wilkinson, Advanced Inorganic Chemistry, 4th Edition, Wiley, New York, 1980, p 699.

${ }^{6}$ M. Nyman, T. M. Nenoff, and T. J. Headley, "Characterization of UOP IONSIV IE-911", Sandia Report

SAND2001-0999, June 2001. 